Nes, A.A.G., Dulmen, S. van, Eide, E., Finset, A., Kristjánsdóttir, O.B., Steen, I.S., Eide, H. The development and feasibility of a web-based intervention with diaries and situational feedback via smartphone to support self-management in patients with diabetes type 2 . Diabetes Research and Clinical Practice: 2012, 97(3), 385-393

\begin{tabular}{|l|l|}
$\begin{array}{l}\text { Postprint } \\
\text { Version }\end{array}$ & 1.0 \\
\hline Journal website & $\frac{\text { http://www.diabetesresearchclinicalpractice.com/article/S0168-8227(12)00153- }}{\underline{\text { 2/abstract }}}$ \\
\hline Pubmed link & $\underline{\text { http://www.ncbi.nlm.nih.gov/pubmed/22578890 }}$ \\
\hline DOI & $10.1016 /$ j.diabres.2012.04.019
\end{tabular}

This is a NIVEL certified Post Print, more info at http://www.nivel.eu

\title{
The development and feasibility of a web-based intervention with diaries and situational feedback via smartphone to support self-management in patients with diabetes type 2 is
}

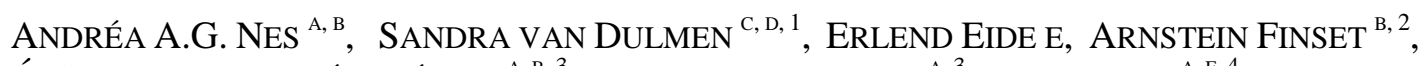
ÓlÖF BIRNA KRISTJÁNSDÓtTIR ${ }^{\text {A, B, } 3}$, IDA SYNNøVE STEEN ${ }^{\text {A, } 3}$, HiLdE EIDE ${ }^{\text {A, F, } 4}$

${ }^{a}$ Institute of Nursing, Oslo and Akershus University College, Falbesgate, 5, 0170 Oslo, Norway

${ }^{\mathrm{b}}$ Department of Behavioral Sciences in Medicine, University of Oslo, Domus Medica Gaustad Sognsvannsveien 9, 0372 Oslo, Norway

${ }^{c}$ NIVEL (Netherlands Institute for Health Services Research), Otterstraat 118-124, 3513 CR Utrecht, The Netherlands

${ }^{\mathrm{d}}$ Radboud University Nijmegen Medical Center, Department of Primary and Community Care, The Netherlands

${ }^{\mathrm{e}}$ Edesign, Kirsebærstien 3a, 3124 Tønsberg, Norway

${ }^{f}$ Faculty of Health Sciences, Buskerud University College, Papirbredden - Drammen kunnskapspark Grønland 58, 3045 Drammen, Norway

\begin{abstract}
Aims: The aim of the study was to develop and test the feasibility of a three months web-based intervention, delivered by a smartphone to support selfmanagement in patients with type 2 diabetes.

Methods: The intervention included use of a smartphone enabling access to daily web-based diaries and individualized written situational feedback. The participants registered their eating behavior, medication taking, physical activities and emotions three times daily using the mobile device. They also registered their fasting blood glucose level in the morning diary. A therapist had immediate access to submitted diaries and used the situational information to formulate a personalized feedback based on Acceptance Commitment Therapy. The purpose of the diaries and the situational feedback was to stimulate selfmanagement.
\end{abstract}


Nes, A.A.G., Dulmen, S. van, Eide, E., Finset, A., Kristjánsdóttir, O.B., Steen, I.S., Eide, H. The development and feasibility of a web-based intervention with diaries and situational feedback via smartphone to support self-management in patients with diabetes type 2 . Diabetes Research and Clinical Practice: 2012, 97(3), 385-393

Results: Eleven of the fifteen participants included in the study completed the intervention, which was evaluated as supportive and meaningful. Most of the participants reported positive life style changes. The response rate to the daily registration entries was good and few technical problems were encountered.

Conclusions: The described intervention is feasible and should be tested out in a large-scale study. The developed smartphone application seems a promising tool for supporting patients with type 2 diabetes to make important life style changes.

\section{INTRODUCTION}

Self-management is an important and evidence-based component of treatment and care for patients with type 2 diabetes ${ }^{[1]}$ and ${ }^{[2]}$, and there is an increasing demand for interventions to support and enhance self-management. One such intervention is Cognitive Behavioral Therapy (CBT), which has been shown to improve diabetes self-management programs ${ }^{[3]}$, ${ }^{[4]}$ and ${ }^{[5]}$. However, most CBT interventions take place in a clinical setting on a weekly basis or even less. Patients usually receive feedback on dysfunctional cognitions and behaviors retrospectively and may find it difficult to adequately incorporate them into daily life. Achieving individual improvements in self-management may be more effective when the patients receive quick and continuous responses from therapists ("situational feedback") using mobile communication technology, i.e., any place, any time.

Web-based CBT and mobile phone interventions are increasingly used to support people with diabetes ${ }^{[6]},{ }^{[7]},{ }^{[8]},{ }^{[9]}$ and ${ }^{[10]}$ and other health problems ${ }^{[11]}$, and several studies have shown effects similar to that of face-to-face CBT ${ }^{[11]},{ }^{[12]}$ and ${ }^{[13]}$. Studies that, in addition to web based CBT, used methods of communicating with participants, such as short message service (SMS), were even more effective in supporting behavioral change ${ }^{[14]}$.

A relatively recent development within CBT is Acceptance and Commitment Therapy (ACT) called the 3rd generation of CBT. ACT differs from traditional forms of CBT by focusing on articulating and clarifying one's values, on acceptance of one's thoughts, feelings and sensations and on mindfulness together with commitment to behavioral change. Individuals are stimulated to be more flexible and to accept, rather than struggle with, unwanted and dysfunctional disease-related thoughts and emotions. ACT aims at helping people to clarify their personal values, to develop changes or maintain valued behaviors and commit to them ${ }^{[15]}$ and ${ }^{[16]}$. Treatments based on ACT for several chronic diseases are increasing worldwide and a large number of randomized control trials confirm positive effects on health outcomes ${ }^{[17]}$. ACT has also been successfully applied to support diabetes selfmanagement ${ }^{[18]}$.

At present few studies have used web-based ACT to support people with health problems ${ }^{[19]}$ and ${ }^{[20]}$ and, to our knowledge, no study has yet investigated the feasibility of delivering an intervention based on ACT through a smartphone using written "situational feedback" to stimulate self-management in people with type 2 diabetes. The aim of this pilot study was to develop and investigate the feasibility of such an intervention. 
Nes, A.A.G., Dulmen, S. van, Eide, E., Finset, A., Kristjánsdóttir, O.B., Steen, I.S., Eide, H. The development and feasibility of a web-based intervention with diaries and situational feedback via smartphone to support self-management in patients with diabetes type 2 . Diabetes Research and Clinical Practice: 2012, 97(3), 385-393

\section{MATERIALS AND METHODS}

\subsection{Study sample}

The pilot study was conducted in Oslo, Norway, between April 2010 and September 2010 and was approved by the Regional Ethical Committee. The intention was to recruit the participants through general practitioners (GPs) and to include 10-15 participants with type 2 diabetes to test the feasibility of the intervention. Because of the difficulty in recruiting patients through their GP's, the social network of the researchers was also informed about the project and persons asked if they knew potential candidates. The potential candidates that met the inclusion criteria received a letter describing the study. Those interested in participating met with the researcher (AAGN) and received additional information. After receiving complementary information, the patients who agreed to participate in the project, signed an informed consent form.

\subsection{The intervention}

The intervention included use of smartphones with four principal elements: (1) An Internet program that made possible the connection with a secure server to access the daily online entries; (2) Individualized written situational feedback; (3) Installed audio files with mindfulness and relaxation exercises; and (4) an installed healthcare tool the Few Touch Application (FTA). The intervention lasted for three months. Three daily diaries were filled in by the participants during the entire period. Daily written situational feedbacks were given during the first month followed by weekly feedbacks during the next two months. The intervention was developed by a multidisciplinary group that included a clinical communication researcher, a diabetic researcher, a nurse with clinical experience with diabetes and two nurse researchers with general clinical experience and a nutritionist. The intervention was also built on experience with similar interventions for two other patient groups; irritable bowel syndrome ${ }^{[21]}$, and chronic widespread pain ${ }^{[19]}$. The theoretical framework was based on ACT; aiming to stimulate valued behavior change and acceptance of disturbing thoughts and feelings. Identifying and working with values and valued activities was emphasized, as recommended by Gregg for people with type 2 diabetes ${ }^{[18]}$ and ${ }^{[22]}$.

\subsection{Start meeting face-to-face and initial telephone consultation}

The intervention started with an individual meeting between the participants and the researcher (AAGN). Participants were informed about the intervention. Each participant borrowed a smartphone (Samsung Omnia i 900) to use during the intervention period. They were taught how to use the smartphone, to fill in the diaries, to read the feedbacks, to hear the sound files and to use the FTA. All the verbal information received was written down in an instruction manual, delivered together with the smartphones, where the participants could consult if necessary. The participants took a blood test and filled in the study assessment instruments in this first meeting.

The participants also received a notebook with written exercises consisting of tasks to identify life values according to the ACT framework. In this notebook, they also could write about their current situation and their goals for health-related behavior. They were encouraged to work with the notebook at home, but it was up to them to take this decision. 
Nes, A.A.G., Dulmen, S. van, Eide, E., Finset, A., Kristjánsdóttir, O.B., Steen, I.S., Eide, H. The development and feasibility of a web-based intervention with diaries and situational feedback via smartphone to support self-management in patients with diabetes type 2 . Diabetes Research and Clinical Practice: 2012, 97(3), 385-393

In addition, the therapist (ISS), who had the main responsibility to write the feedback, contacted the participants by telephone before the beginning of the intervention. The intention with this initial contact was to create a relationship and get information about the need for support.

\subsection{Online diaries}

The online diaries included 16-19 questions chosen for supporting self-monitoring and awareness of health behavior, thoughts, feelings and applied self-management strategies (see Table 1). Most of the questions were answered by choosing predefined alternatives or by scoring on a six-point Likert scale. The diaries included questions about current level of blood glucose, diet, medicine, achieved activities, feelings and a brief evaluation of the received feedback. The diaries also included a comment field giving participants the opportunity to write a short personal message to the therapist.

\section{[TABLE 1]}

The participants filled in three diaries daily by receiving SMS alerts on the borrowed smartphone. Each SMS message had a link to a secure web site where the diaries could be opened, filled in and submitted. If the diary entry was not returned within $45 \mathrm{~min}$, the server automatically sent an SMS reminder message. Two reminders within $1 \mathrm{~h}$ per diary were allowed. The submission of the diary was only possible when it was fully completed within $90 \mathrm{~min}$. Then the diary was closed.

The participants could decide the most convenient time to receive the morning and evening diary. This agreement was concluded at the first meeting with the

participants and was intended to adapt the intervention to the participants' daily routines. The web server chose the midday diary entry at random. The number of daily diaries was necessary to identify emotions, thoughts and coping, that usually fluctuate during the day. The purpose of including one at a randomly chosen time was based on the experience of a previous study ${ }^{[19]}$ and the intension was to increase the validity of the assessment.

\subsection{Written situational feedback}

The therapist (ISS), a nurse with clinical experience, wrote tailored feedbacks in collaboration with the researcher (AAGN). In the beginning and when needed, the supervisor (HE) contributed through suggestions concerning the focus and content of the feedbacks. The written feedback was based on ACT with a focus on values, value-based behavior, mindfulness and acceptance. The information from the submitted diaries, as well as the overall aims expressed in the meetings with the participants, provided input for the feedback. The multi-disciplinary group supported development of the content of the feedback during the first period of the study.

\subsection{Automatic transfer of blood glucose level to the smartphone}

A special application developed for automatic transfer of the registered blood glucose value from the glucose meter to the smartphone, the FTA, was used. The measured blood glucose levels were stored in the smartphone and could be seen retrospectively and in a diagram form by the participant.

The FTA is a mobile phone-based system. The system also includes software for recording food habits and physical activity. The system provides feedback (smile faces), depending on how users perform in relation to their own personal goals. This 
Nes, A.A.G., Dulmen, S. van, Eide, E., Finset, A., Kristjánsdóttir, O.B., Steen, I.S., Eide, H. The development and feasibility of a web-based intervention with diaries and situational feedback via smartphone to support self-management in patients with diabetes type 2 . Diabetes Research and Clinical Practice: 2012, 97(3), 385-393

application has been tested in an earlier study and is described in a scientific paper [23]

\subsection{Evaluation measures}

\subsubsection{Feasibility of the intervention}

At the end of the intervention, the participants received a questionnaire to assess their experience with the study. The questionnaire had five main areas with the number of items varying from eight to twenty: (a) participation in the project (12 items), (b) use of smartphone (20 items), (c) daily diaries (12 items), (d) the received feedbacks (12 items), and (e) self-management (8). The scoring range in the answers was on fivepoint Likert scales from zero "totally disagree" to five "totally agree". The participants have also answered seven questions about the project structure. The development of this questionnaire was based on a similar questionnaire from a previous study ${ }^{[19]}$. As the aim of this study was to develop an intervention in line with the patients' needs, the patients were also invited to participate in two semistructured interviews conducted by researcher AAGN. In these interviews, the patients told about their experience with the intervention and provided suggestions for improvement. An interview guide was used to maintain the desired focus on the topics to be addressed. These interviews were performed halfway through and after the completion of the study. The interviews were recorded and transcribed. The therapist's (ISS) and the researcher's (AAGN) experiences were also taken into account in the feasibility evaluation process.

\subsubsection{Assessment instruments}

Health related measures were collected before and after intervention as HBA1c, BMI, ADDQoL-19 (Audit of Diabetes Dependence Quality of Life) and Problem Areas in Diabetes (PAID).

ADDQoL-19 ${ }^{[24]}$ is a diabetes related quality of life questionnaire designed to assess to what extent diabetes may affect different aspects of life. The ADDQoL includes two introductory questions and eighteen specific items, with the purpose of assessing, from the participant's perspective, how much better/worse his or her life quality would be if he/she did not have diabetes and how important each of these nineteen aspects of life quality are for the individual ${ }^{[24]}$.

$\boldsymbol{P A I D}^{[25]}$ is a brief self-report measure of diabetes-related distress that has been found to be useful in patients with diabetes (both type 1 and type 2). PAID scores have been found to show positive associations with HbA1c, and are major predictors of poor adherence to treatment not involving general emotional distress.

\subsubsection{Blood test}

A blood test was taken at the GPs office before and after the intervention to evaluate the HBA1c level, fasting glucose level, HDL cholesterol, LDL cholesterol and triglycerides. The blood test results were registered in the patients' journal.

\subsection{Analyses}

Descriptive statistics as means and frequencies were calculated using SPSS version 18. A descriptive summary of the information extracted from the interviews was made, the content was analyzed and themes identified. 
Nes, A.A.G., Dulmen, S. van, Eide, E., Finset, A., Kristjánsdóttir, O.B., Steen, I.S., Eide, H. The development and feasibility of a web-based intervention with diaries and situational feedback via smartphone to support self-management in patients with diabetes type 2 . Diabetes Research and Clinical Practice: 2012, 97(3), 385-393

\section{RESULTS}

\subsection{Study sample}

Five GP offices were invited to participate in this pilot study and two agreed. In total, thirty-six people were invited to participate and fifteen agreed to participate in this study: Five women and ten men aged 46-71 years (mean = 59.6). Thirteen

participants were recruited from their GP's office and 2 from researchers' network. Eleven of the fifteen patients were employed and four were retired. Three were single, two were divorced, one was cohabiting and nine were married. Four participants dropped out and eleven completed the study. The dropouts were related to participants' conviction that the project was too time consuming, despite their being positive at the first meeting, 1-2 days after the inclusion they contacted the researcher and explained that they believed it would take too much time to fill in the diaries three times daily. It is important to emphasize that these persons did not start the intervention and that they returned the smartphone. Mean average HBA1c level the week before inclusion was $7.39 \%(\mathrm{SD}=1.11 \%)$ and $6.9 \%(\mathrm{SD}=0.8 \%)$ at the end of intervention. The individual scores on fast blood glucose, BMI, emotional distress (PAID) and quality of life (ADDQoL19) are shown in Table 2.

\section{[TABLE 2]}

\subsection{Feasibility evaluation}

\subsubsection{Evaluation based on questionnaires}

The patients were satisfied with the participation in the project and most of them perceived this experience as supportive, meaningful and motivating (see Table 3).

\section{[TABLE 3]}

The use of a smartphone was challenging for some patients, but the majority of them found the phones user friendly. The main problems were the use of touch display (unusual, illogical with small letters) and the size of the telephone (too big).

The diary response rate ranged from $21 \%$ to $97 \%$ (see ${ }^{\text {Table } 2}$ ) with an average of $68 \%$. Most of the participants reported the diaries as a positive experience and judged the content and questions in the diaries to be easy, inspiring and useful (see ${ }^{\text {Table }} 3$ ). The patients also ranked satisfaction with the content of the feedback at a high level. They reported that the feedback helped them to manage their diabetes by reinforcing favorable coping strategies. The majority was able to follow the advices related to physical and relaxation exercises. The feedback also encouraged the participants to follow their diet plan, check their blood glucose level and take their medication at the correct time and dosage. Just one participant reported no changes in the advising areas and three did not feel motivated to do relaxation exercises (see Table 4).

\section{[TABLE 4]}

Seven participants evaluated three diaries per day as acceptable and considered the number of questions in the diary and length of the intervention as suitable. One participant preferred more questions, while two wished to decrease the number of diaries and questions. Seven participants agreed that one feedback daily during four 
Nes, A.A.G., Dulmen, S. van, Eide, E., Finset, A., Kristjánsdóttir, O.B., Steen, I.S., Eide, H. The development and feasibility of a web-based intervention with diaries and situational feedback via smartphone to support self-management in patients with diabetes type 2. Diabetes Research and Clinical Practice: 2012, 97(3), 385-393

weeks was acceptable, while three reported that they were too many. Two participants evaluated weekly feedback as too little and eight were completely satisfied. Generally, most of the participants were satisfied with the structure of the intervention (see Table 5).

\section{[TABLE 5]}

\subsubsection{Interviews}

Only one of the participants that completed the intervention was not interviewed twice. No changes were done in the intervention after the first interview with the participants. The information collected through the interviews midway and at the end of the project gave some additional information about the patient's perception and evaluation of the intervention. The patients experienced the intervention to be useful. They reported the content and questions in the diaries to be relevant and understandable, and that filling in the diaries gave them a better insight into their diabetes, increased their coping and self-management strategies. However, they missed a variation in the questions and wanted weekends free from the diaries. They also mentioned that a long period of filling in diaries led to decreasing awareness. On the other hand, this period also contributed positively to increasing their honesty in answering the diary questions. The feedback messages were experienced as personal and relevant to the patients' current situation. The patients reported that the feedback helped them to define their own goals based on health values, identify barriers related to goals achievement and develop strategies to overcome the barriers. They reported that they became committed to their values and goals and most of them were willing to change their life style to achieve a good health status. Those who did not work with their goals for achieving better diabetes self-management also reported a sense of guilt.

The patients would have liked to receive more information about diet, as they reported that this theme was difficult to deal with. The stimuli to perform physical activities helped the patients to be more active. Only a few patients used the sound file with mindfulness exercises. The patients appreciated the possibility to monitor their blood glucose level by using the FTA. However, they also reported a frequently occurring technical failure transferring the blood glucose level from the glucose meter to the smartphone.

Other difficulties with the intervention were also reported. As the smartphone with the intervention application was borrowed, the participants found it uncomfortable and sometimes inconvenient to take the smartphone along with their mobile. Some experienced problems with submitting the diaries, e.g., that the registered information disappeared and they had to fill in the diary again. Generally, the diary questions related to their feelings were evaluated as difficult to answer. The participants had doubts especially about how to interpret these questions. The majority of participants would have liked to have had an overview of all feedback messages, where they could have found and read them again when they wanted. One participant would have preferred one intervention with group interaction where the participants could motivate each other. The same participant also reported increased awareness about how important diabetes self-management was to avoid later diabetes complication. However, he did not manage to modify any life habits 
Nes, A.A.G., Dulmen, S. van, Eide, E., Finset, A., Kristjánsdóttir, O.B., Steen, I.S., Eide, H. The development and feasibility of a web-based intervention with diaries and situational feedback via smartphone to support self-management in patients with diabetes type 2 . Diabetes Research and Clinical Practice: 2012, 97(3), 385-393

and his HBA1c level increased during the intervention period. After the end of the pilot study, this participant, together with his GP, investigated alternative diabetes treatments trying to find one that was suitable for him.

In summary, the intervention was perceived as supportive in breaking habits and establishing new health behavior for most of participants.

\subsubsection{The therapist's and researcher's clinical impressions}

The therapist (ISS) and researcher (AAGN) felt that an interactive relationship was established with most of the patients. Both believed that the first meeting and the telephone conversation prior to the intervention were important to insure the feasibility of the intervention. However, it was challenging to achieve the goal of always being empathic when the communication with nonverbal signals and dialog were missing.

The therapist analyzed the participants' answers in the three last diary entries before writing a feedback. It was time consuming for the therapist to get an overview of the diaries. The system did not show this information as a summary, and it was necessary to navigate through several pages to get needed information. In addition the therapist had to look at the feedback history to avoid repeating information. A feedback "bank" was developed by the therapist nurse (ISS) and the researcher (AAGN, also a nurse) with contribution from other health professionals; a researcher in therapeutic communication (HE), a researcher in diabetes care, a nutritionist, and one other nurse researcher with clinical experience. After the first month, when the feedback bank was ready, the time used to formulate the feedbacks was 15-20 min. We had expected that the participants had a sufficient knowledge about diabetes and diabetes treatment. This was not the case. The intention with the feedback was to stimulate to self-management, but it was often necessary to provide basic information about diabetes. For some patients the increased understanding of their disease was enough to change their life style.

\subsection{Technical issues}

Problems with the Internet connection were reported as validation errors and system breakdown. Validation error is a message from the system that appears when it was not possible to send the completed diary back to the server and happened occasionally when participants used too much time to complete the diaries (this was part of data security) or when the Internet connection was poor. Some participants had vacations during the intervention period and those reported difficulties in submitting the diaries especially when they were abroad. We had one system breakdown during the pilot period. The system was restored to working order the day after the problem was reported. The researcher (AAGN) was often contacted because of these problems. Participants reported technical problems as frustrating and demotivating.

\section{DISCUSSION}

In this pilot study, we developed and investigated the feasibility of delivering a web based intervention on a smartphone to patients with type 2 diabetes, including the applicability of the chosen instruments to assess diabetes-related quality of life and diabetes-related distress. Although we have chosen HBA1c as an indicator of 
Nes, A.A.G., Dulmen, S. van, Eide, E., Finset, A., Kristjánsdóttir, O.B., Steen, I.S., Eide, H. The development and feasibility of a web-based intervention with diaries and situational feedback via smartphone to support self-management in patients with diabetes type 2 . Diabetes Research and Clinical Practice: 2012, 97(3), 385-393

behavioral change, we realize that this measurement itself is not enough to draw any conclusions concerning behavioral change. In a further study, an instrument assessing self-management will therefore be needed.

The number of completed diaries, the experiences of the therapist (ISS), researcher (AAGN) and the evaluations by the participants all pointed to a feasible intervention. Recruitment from GPs was challenging and the need to find new ways of recruitment increased over time. Other studies have reported similar experiences ${ }^{[19]}$ and ${ }^{[26]}$. A possibility in the future can be delivering this intervention in health institutions which deliver self-management courses for people with type 2 diabetes.

The therapist's impression was that the participants did not have much knowledge about their diabetes. If the participants were recruited from health institutions, this would probably have improved the participants' basic knowledge of diabetes and would have made the participant group more homogeneous. Experience with a similar project with chronic pain participants showed that recruitment from the rehabilitation center was more positive than recruitment from GPs ${ }^{[19]}$. Most participants were satisfied with the intervention and improvements on measures such as HBA1c, fast blood glucose, BMI, ADDQoL19 and PAID were observed. However, because of the small sample size, these results are of limited value. Studies based on mobile phone intervention that have been investigated in a recent metaanalysis, showed that improvements in glycemic control and self-management for patients with type 2 diabetes were statistically significant ${ }^{[7]}$.

The intervention's framework, based on ACT, is considered acceptable and a larger study is recommended. There are potentials for improvement that should be analyzed by performing the following activities: (1) Variation of the content of the daily diaries in the project period; (2) evaluation of how to stimulate a better use of the sound files with mindfulness exercises (e.g., emphasizing the benefits of these in the first meeting with the participants); (3) further development of the method for providing feedback. This method was very time consuming in the beginning, but was reduced to an acceptable level by the end of the study. The goal with an intervention will be to prove a methodology feasible for clinical use. Then a further reduction of the time to give feedback will be important. A suggestion is to give the responsibility of writing feedbacks to a therapist with clinical experience in type 2 diabetes. This therapist should be trained in ACT in the initial stage of the project. The knowledge acquired in this study can give the basis for the development of such training. Some participants experienced becoming more conscious about their feelings. Guilt was frequently mentioned, as for example, when they perceived their own effort as too limited to achieve their health related goals. This is also found in a qualitative study with patients with chronic pain taking part in a similar study ${ }^{[27]}$. According to Gregg, 2007 this is also a common feeling for type 2 diabetes patients and negatively influences self-management ${ }^{[2]}$. With an intervention based on ACT, participants can learn, among other things, to accept their negative thoughts and feelings in order to achieve psychological flexibility and consequently improvement in diabetes selfmanagement ${ }^{[18]}$.

The lack of nonverbal communication was a challenge for the therapist. Face-to-face communication usually provides valuable information that might change the therapist's interpretation of the patient's situation and thereby alter the therapist's strategy for treatment. This challenge needs to be discussed and the consequences of missing nonverbal communication have to be investigated. Already in 2000, 
Nes, A.A.G., Dulmen, S. van, Eide, E., Finset, A., Kristjánsdóttir, O.B., Steen, I.S., Eide, H. The development and feasibility of a web-based intervention with diaries and situational feedback via smartphone to support self-management in patients with diabetes type 2 . Diabetes Research and Clinical Practice: 2012, 97(3), 385-393

Childress wrote an article analyzing the ethical aspect of online interventions and concluded, among other things, that theoretical models to deliver a text based format intervention need to be developed and patients must be informed that risks related to this relatively new method of treatment is unknown ${ }^{[28]}$. Further studies are needed to investigate effectiveness, possible therapeutic processes and mechanisms explaining possible effects, application in daily care and the impact of the lack of nonverbal communication in the intervention. It is important to emphasize that the researcher (AAGN) was involved in writing the feedbacks, performing and evaluating of the interviews and this may have influenced the evaluation results.

Improvements in the system are necessary to avoid temporary problems with submitting diaries as they may cause frustration and affect dropout rates. For the therapist, a better overview over submitted diaries would facilitate the writing of the feedbacks. Revisions of the technological platform should also include a personal webpage where the patient could access his/her own diaries and feedback. Future interventions should be more flexible in the content of the diaries, by tailoring this more to the patient's wish for change. The possibility of participants using their own mobile phones instead of borrowed ones would be preferable.

The results of this pilot study indicate that written online situational feedback via a smartphone is a feasible intervention for people with type 2 diabetes. The daily diaries filled by the participants may have supported self-monitoring. The Internet connection made it possible to submit the diaries online to become immediately available to a therapist and thus allowing them to give the patient situational feedback via a text message based on updated information. This intervention needs to be tested in a randomized study to investigate therapeutic effectiveness on diabetes related life style changes.

\section{CONFLICT OF INTEREST}

The authors declare that they have no conflict of interest.

\section{ACKNOWLEDGMENTS}

AAGN, ISS, and HE participated in the development of the intervention. SvD, OBK and AF contributed with experiences from a previous study. AAGN recruited participants. ISS was the therapist. AAGN collected the study measures, revised the feedbacks and performed the interviews. HE supervised the study. EE was responsible for the design and development of the technological system. AAGN and HE analyzed the data and drafted the manuscript. All authors read and approved the final manuscript.

A warm thanks to the patients helping developing this intervention.

AAGN was funded partly by RCN grant 196364 and partly by OAUC strategic funds. ISS was funded by OAUC strategic funds. The other co-authors were funded by their own institutions.

\section{REFERENCES}

[1] Glasgow RE, Boles SM, McKay HG, Feil EG, Barrera Jr M. The D-Net diabetes selfmanagement program: long-term implementation, outcomes, and generalization results. Prev Med 2003;36(4):410-9. 
Nes, A.A.G., Dulmen, S. van, Eide, E., Finset, A., Kristjánsdóttir, O.B., Steen, I.S., Eide, H. The development and feasibility of a web-based intervention with diaries and situational feedback via smartphone to support self-management in patients with diabetes type 2 . Diabetes Research and Clinical Practice: 2012, 97(3), 385-393

[2] Norris SL, Lau J, Smith SJ, Schmid CH, Engelgau MM. Selfmanagement education for adults with type 2 diabetes: a meta-analysis of the effect on glycemic control. Diabetes Care 2002;25(7):1159-71.

[3] Ismail K, Winkley K, Rabe-Hesketh S. Systematic review and meta-analysis of randomised controlled trials of psychological interventions to improve glycaemic control in patients with type 2 diabetes. Lancet 2004;363(9421):1589-97.

[4] Winkley K, Ismail K, Landau S, Eisler I. Psychological interventions to improve glycaemic control in patients with type 1 diabetes: systematic review and meta-analysis of randomised controlled trials. Br Med J (Clin Res Ed) 2006;333(7558):65.

[5] Welschen LMC, van Oppen P, Dekker JM, Bouter LM, Stalman WAB, Nijpels G. The effectiveness of adding cognitive behavioural therapy aimed at changing lifestyle to managed diabetes care for patients with type 2 diabetes: design of a randomised controlled trial. BMC Public Health 2007;7:74.

[6] Kouris I, Mougiakakou S, Scarnato L, lliopoulou D, Diem P, Vazeou A, Koutsouris D. Mobile phone technologies and advanced data analysis towards the enhancement of diabetes self-management. Int J Electron Healthc 2010;5(4):386-402.

[7] Liang X, Wang Q, Yang X, Cao J, Chen J, Mo X, Huang J, Wang L, Gu D. Effect of mobile phone intervention for diabetes on glycaemic control: a meta-analysis. Diabet Med J Br Diabet Assoc 2011;28(4):455-63.

[8] Chomutare T, Fernandez-Luque L, Arsand E, Hartvigsen G. Features of mobile diabetes applications: review of the literature and analysis of current applications compared against evidence-based guidelines. J Med Internet Res 2011;13(3):e65.

[9] Quinn CC, Gruber-Baldini AL, Shardell M, Weed K, Clough SS, Peeples M, Terrin M, Bronich-Hall L, Barr E, Lender D. Mobile diabetes intervention study: testing a personalized treatment/behavioral communication intervention for blood glucose control. Contemp Clin Trials 2009;30(4): 334-46.

[10] Faridi Z, Liberti L, Shuval K, Northrup V, Ali A, Katz DL. Evaluating the impact of mobile telephone technology on type 2 diabetic patients' self-management: the NICHE pilot study. J Eval Clin Pract 2008;14(3):465-9.

[11] Cuijpers P, Van Straten A, Andersson G. Internetadministered cognitive behavior therapy for health problems: a systematic review. J Behav Med 2008;31(2): 169-77.

[12] Spek V, Cuijpers P, Nykll'cek I, Riper H, Keyzer J, Pop V. Internet-based cognitive behaviour therapy for symptoms of depression and anxiety: a meta-analysis. Psychol Med 2007;37(03):319-28.

[13] Barak A, Hen L, Boniel-Nissim M, Shapira N. A comprehensive review and a metaanalysis of the effectiveness of Internet-based psychotherapeutic interventions. J Technol Hum Serv 2008;26(2): 109-60.

[14] Webb T, Joseph J, Yardley L, Michie S. Using the Internet to promote health behavior change: a systematic review and meta-analysis of the impact of theoretical basis, use of behavior change techniques, and mode of delivery on efficacy. J Med Internet Res 2010;12(1).

[15] Hayes S, Strosahl K, Wilson K. Acceptance and commitment therapy: an experiential approach to behavior change. The Guilford Press; 2003.

[16] Hayes SC, Luoma JB, Bond FW, Masuda A, Lillis J. Acceptance and commitment therapy: model, processes and outcomes. Behav Res Ther 2006;44(1):1-25.

[17] Powers MB, Zum Vo" rde Sive Vo" rding MB, Emmelkamp PMG. Acceptance and commitment therapy: a meta-analytic review. Psychother Psychosom 2009;78(2):73-80.

[18] Gregg JA, Callaghan GM, Hayes SC, Glenn-Lawson JL. Improving diabetes selfmanagement through acceptance, mindfulness, and values: a randomized controlled trial. J Consult Clin Psychol 2007;75(2):336-43.

[19] Kristjansdottir O, Fors E, Eide E, Finset A, van Dulmen S, Wigers S, Eide H. Written online situational feedback via mobile phone to support self-management of chronic widespread pain: a usability study of a Web-based [20] Interactive psychological analysis methods within a web-based intervention for wellbeing management, http://www.ementalhealthsummit.com/documents/1_11_2\%20EMS09_S1_11_KaipainenK_ Final.pdf. 
Nes, A.A.G., Dulmen, S. van, Eide, E., Finset, A., Kristjánsdóttir, O.B., Steen, I.S., Eide, H. The development and feasibility of a web-based intervention with diaries and situational feedback via smartphone to support self-management in patients with diabetes type 2 . Diabetes Research and Clinical Practice: 2012, 97(3), 385-393

[21] Oerlemans S, van Cranenburgh O, Herremans P-J, Spreeuwenberg P, van Dulmen S. Intervening on cognitions and behavior in irritable bowel syndrome: a feasibility trial using PDAs. J Psychosom Res 2011;70(3):267-77.

[22] Gregg JA. The diabetes lifestyle book: facing your fears and making changes for $a^{\circ}$ long and healthy life. Oakland: New Harbinger Publications; 2007.

[23] Arsand E, Tatara N, Østengen G, Hartvigsen G. Mobile phone-based self-management tools for type 2 diabetes: the few touch application. J Diabet Sci Technol 2010;4(2):328-36.

[24] Bradley C, Todd C, Gorton T, Symonds E, Martin A, Plowright R. The development of an individualized questionnaire measure of perceived impact of diabetes on quality of life: the ADDQoL. Qual Life Res Int J Qual Life Aspects Treat Care Rehabil 1999;8(1-2):79-91.

[25] Snoek FJ, Pouwer F, Welch GW, Polonsky WH. Diabetesrelated emotional distress in Dutch and U.S. diabetic patients: cross-cultural validity of the problem areas in diabetes scale. Diabetes Care 2000;23(9):1305-9.

[26] van der Wouden J, Blankenstein A, Huibers M, van der Windt D, Stalman W, Verhagen A. Survey among 78 studies showed that Lasagna's law holds in Dutch primary care research. J Clin Epidemiol 2007;60(8):819-24.

[27] Jelin E, Granum V, Eide H. Experiences of a web-based nursing interventioninterviews with women with chronic musculoskeletal pain. Pain Manage Nurs 2012;13(1):2-10.

[28] Childress AC. Ethical issues in providing online psychotherapeutic interventions. J Med Internet Res 2000;2(1):e5.

TABLES

\section{Table 1 - Content and timing of diary entries.}

\begin{tabular}{|c|c|c|c|c|c|}
\hline Content & $\begin{array}{l}\text { Morning } \\
\text { diary }\end{array}$ & $\begin{array}{l}\text { Midday } \\
\text { diary }\end{array}$ & $\begin{array}{l}\text { Evening } \\
\text { diary }\end{array}$ & $\begin{array}{l}\text { Example of questions }(\mathrm{Q}) \\
\text { and statements }(\mathrm{S})\end{array}$ & Example of answers (A) \\
\hline Glucose-Registration & $\mathrm{x}$ & & & Q: My fasting blood glucose level is... & A: Open answer \\
\hline \multirow[t]{2}{*}{ Evaluation of sleep } & $\mathrm{x}$ & & & Q: Last night I slept... & $\begin{array}{l}\text { A: Three-point Likert scale from } \\
\text { "well" to "bad" }\end{array}$ \\
\hline & $\mathrm{x}$ & & & Q: I awoke during the night because I was... & $\begin{array}{l}\text { A: List of alternatives to choose } \\
\text { including (hungry, thirsty and } \\
\text { sweating) }\end{array}$ \\
\hline Plan for the day & $\mathrm{x}$ & $\mathrm{X}$ & $\mathrm{x}$ & Q: In the next couple of hours, I plan to... & $\begin{array}{l}\text { A: List of alternatives to choose } \\
\text { (measure of blood glucose, } \\
\text { taking of medications, following } \\
\text { diet plan and physical activities } \\
\text { including exercise, relaxing and } \\
\text { stretching) }\end{array}$ \\
\hline Emotions & $\mathrm{x}$ & $\mathrm{x}$ & $\mathrm{x}$ & $\begin{array}{l}\text { S: Right now I am grateful... (several works } \\
\text { that represents good and bad feelings) }\end{array}$ & $\begin{array}{l}\text { A: Six-point Likert scale from "agree } \\
\text { totally" to "disagree totally" }\end{array}$ \\
\hline Evaluation & & $\mathrm{x}$ & $\mathrm{x}$ & $\begin{array}{l}\text { Q: How satisfied am I with ... since the } \\
\text { last entry (several questions related to } \\
\text { participants plan for the day)? }\end{array}$ & $\begin{array}{l}\text { A: Six-point Likert scale from "very } \\
\text { satisfied" to "very dissatisfied" }\end{array}$ \\
\hline $\begin{array}{l}\text { Evaluation of } \\
\text { feedback }\end{array}$ & & & $\mathrm{x}$ & S: The feedback has helped me... & $\begin{array}{l}\text { A: List of alternatives to choose } \\
\text { related to participants plan for } \\
\text { the day }\end{array}$ \\
\hline $\begin{array}{l}\text { Open space for } \\
\text { comments }\end{array}$ & $\mathrm{x}$ & $\mathrm{x}$ & $\mathrm{x}$ & & \\
\hline $\begin{array}{l}\text { Total number } \\
\text { of questions }\end{array}$ & 16 & 12 & 19 & & \\
\hline
\end{tabular}


Table 2 - Assessment scores per participant.

\begin{tabular}{|c|c|c|c|c|c|c|c|c|c|c|c|c|c|c|c|c|c|c|}
\hline \multirow[t]{2}{*}{ Case } & \multirow[t]{2}{*}{ Sex } & \multirow[t]{2}{*}{ Age } & \multicolumn{2}{|c|}{ HBA1c } & \multicolumn{2}{|c|}{ BMI } & \multicolumn{2}{|c|}{$\begin{array}{c}\text { Fast } \\
\text { blood } \\
\text { glucose }\end{array}$} & \multicolumn{2}{|c|}{$\begin{array}{l}\text { ADDQoL19 } \\
\text { overview } 1^{a}\end{array}$} & \multicolumn{2}{|c|}{$\begin{array}{l}\text { ADDQoL19 } \\
\text { overview } 2^{b}\end{array}$} & \multicolumn{2}{|c|}{ ADDQoL19 } & \multicolumn{2}{|c|}{ PAID } & \multirow{2}{*}{$\begin{array}{l}\text { Diary } \\
\text { response } \\
\text { rate } \\
\%\end{array}$} & \multirow{2}{*}{$\begin{array}{c}\text { Feedback } \\
\text { read rate } \\
\%\end{array}$} \\
\hline & & & B & A & B & A & B & A & B & A & B & A & B & A & B & A & & \\
\hline 1 & M & 52 & 7.0 & 7.2 & 35 & 35 & 10.3 & 13.3 & 1 & 1 & -2 & -2 & -1 & -0.63 & 26.25 & 40.00 & 51 & 100 \\
\hline 2 & M & 59 & 9.2 & 7.6 & 20 & 18 & 2.4 & 5.8 & 2 & 2 & -1 & -1 & -1.16 & -2.53 & 18.75 & 25.00 & 97 & 100 \\
\hline 3 & M & 61 & 6.7 & 6.6 & 32 & 32 & 7.7 & 7.3 & 1 & 0.0 & -1 & -1 & -0.16 & -0.11 & 13.75 & 18.75 & 64 & 100 \\
\hline 4 & M & 45 & 6.5 & 6.5 & 31 & 31 & 9.3 & 7.8 & 2 & 2 & -2 & -2 & -3.47 & -3.55 & 38.75 & 36.25 & 51 & 67 \\
\hline 5 & $\mathrm{~F}$ & 65 & 6.1 & 6.6 & 26 & 27 & 7.1 & 9.3 & 1 & & 0.0 & 0.0 & -0.21 & -0.47 & 7.5 & 28.75 & 74 & 92 \\
\hline 6 & $\mathrm{~F}$ & 62 & 8.2 & 6.3 & 43 & 39 & 8.4 & 7.1 & 0.0 & 2 & 0.0 & 0.0 & -0.16 & -0.32 & 16.25 & 11.25 & 62 & 88 \\
\hline 7 & M & 66 & 8.6 & 9.0 & 29 & 29 & 10.2 & 12.3 & 1 & 2 & -2 & -1 & -1.32 & -1 & 43.75 & 36.25 & 21 & 30 \\
\hline 8 & M & 71 & 8.7 & 7.3 & 29 & 26 & 14.2 & 9.7 & 1 & 1 & -1 & -1 & -2.74 & -2.53 & 16.25 & 8.75 & 84 & 88 \\
\hline 9 & $F$ & 63 & 6.3 & 6.3 & 21 & 21 & 6.1 & 5.7 & 0.0 & 0.0 & -2 & -1 & -1.16 & -0.95 & 51.25 & 20.00 & 88 & 75 \\
\hline 10 & M & 50 & 7.6 & 7.1 & 32 & 32 & 8.9 & 9.7 & 2 & 2 & -2 & -1 & -1 & -0.79 & 8.75 & 7.50 & 71 & 100 \\
\hline 11 & $\mathrm{~F}$ & 61 & 6.4 & 6.4 & 25 & 23 & 6.5 & 6.6 & 2 & 2 & -1 & -1 & -1.37 & -0.53 & 33.75 & 15.00 & 86 & 88 \\
\hline
\end{tabular}


Nes, A.A.G., Dulmen, S. van, Eide, E., Finset, A., Kristjánsdóttir, O.B., Steen, I.S., Eide, H. The development and feasibility of a web-based intervention with diaries and situational feedback via smartphone to support self-management in patients with diabetes type 2 . Diabetes

Research and Clinical Practice: 2012, 97(3), 385-393

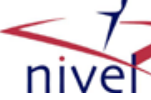

Table 3 - Evaluation of project, diaries and feedback.

\begin{tabular}{|c|c|c|c|c|c|c|c|c|c|c|c|c|c|c|c|}
\hline & \multicolumn{5}{|c|}{$\begin{array}{c}\text { I think it's been ... to } \\
\text { participate in this project }\end{array}$} & \multicolumn{5}{|c|}{$\begin{array}{c}\text { I think it's been ... completing } \\
\text { the diary forms }\end{array}$} & \multicolumn{5}{|c|}{$\begin{array}{l}\text { I think it's been .... } \\
\text { to receive Feedback }\end{array}$} \\
\hline & \multicolumn{3}{|c|}{$\begin{array}{c}\text { Totally } \\
\text { agree }\end{array}$} & \multicolumn{2}{|c|}{$\begin{array}{r}\text { Totally } \\
\text { disagree } \\
\end{array}$} & \multicolumn{3}{|c|}{$\begin{array}{l}\text { Totally } \\
\text { agree }\end{array}$} & \multicolumn{2}{|c|}{$\begin{array}{l}\text { Totally } \\
\text { disagree } \\
\end{array}$} & \multicolumn{3}{|c|}{$\begin{array}{l}\text { Totally } \\
\text { agree }\end{array}$} & \multicolumn{2}{|c|}{$\begin{array}{l}\text { Totally } \\
\text { disagree }\end{array}$} \\
\hline & 1 & 2 & 3 & 4 & 5 & 1 & 2 & 3 & 4 & 5 & 1 & 2 & 3 & 4 & 5 \\
\hline 1. Easy & 4 & 3 & 3 & 1 & 0 & 5 & 4 & 2 & 0 & 0 & 9 & 1 & 1 & 0 & 0 \\
\hline $\begin{array}{l}\text { 2. Timing } \\
\text { consuming }\end{array}$ & 0 & 0 & 5 & 2 & 3 & 0 & 1 & 2 & 4 & 3 & 0 & 0 & 1 & 2 & 7 \\
\hline 3. Positive & 8 & 2 & 0 & 0 & 0 & 5 & 5 & 0 & 0 & 0 & 6 & 3 & 1 & 0 & 0 \\
\hline 4. Supportive & 7 & 3 & 1 & 0 & 0 & 4 & 5 & 1 & 0 & 0 & 5 & 4 & 2 & 0 & 0 \\
\hline 5. Tiring & 0 & 0 & 5 & 1 & 4 & 0 & 1 & 2 & 4 & 3 & 0 & 1 & 1 & 0 & 8 \\
\hline 6. Frustrating & 0 & 1 & 5 & 0 & 4 & 0 & 0 & 4 & 2 & 4 & 0 & 0 & 0 & 3 & 7 \\
\hline 7. Inspiring & 6 & 2 & 2 & 0 & 0 & 4 & 3 & 3 & 0 & 0 & 5 & 3 & 2 & 0 & 0 \\
\hline 8. Meaningful & 6 & 2 & 2 & 0 & 0 & 5 & 1 & 3 & 1 & 0 & 4 & 6 & 1 & 0 & 0 \\
\hline 9. Stressful & 0 & 0 & 1 & 4 & 5 & 0 & 1 & 0 & 4 & 5 & 0 & 1 & 1 & 1 & 7 \\
\hline 10. Confusing & 0 & 1 & 2 & 3 & 4 & 0 & 1 & 1 & 2 & 6 & 0 & 0 & 1 & 2 & 7 \\
\hline 11. Useful & 5 & 5 & 0 & 0 & 0 & 5 & 4 & 1 & 0 & 0 & 4 & 5 & 1 & 0 & 0 \\
\hline 12. Motivational & 7 & 2 & 1 & 0 & 0 & 5 & 4 & 1 & 0 & 0 & 5 & 3 & 2 & 0 & 0 \\
\hline
\end{tabular}

Table 4 - Participants experience with the project, diaries and feedback connected to self-management.

\begin{tabular}{|c|c|c|c|c|c|}
\hline & \multicolumn{4}{|c|}{ Totally agree } & \multirow{2}{*}{$\frac{\text { Totally disagree }}{5}$} \\
\hline & 1 & 2 & 3 & 4 & \\
\hline 1. I've got some methods I can use to manage my diabetes & 3 & 4 & 2 & 0 & 1 \\
\hline $\begin{array}{l}\text { 2. I feel that I have become more aware of the coping strategies } \\
\text { of my participation in this project }\end{array}$ & 7 & 2 & 0 & 1 & 0 \\
\hline 3. I was able to carry out the tasks and the advice I got & 2 & 5 & 2 & 1 & 0 \\
\hline 4. I have been motivated to physical exercise & 5 & 4 & 1 & 1 & 0 \\
\hline 5. I have been motivated to do relaxation exercises & 2 & 4 & 1 & 3 & 0 \\
\hline 6. I have been motivated to follow my diet plan & 3 & 3 & 3 & 1 & 0 \\
\hline 7. I have been motivated to check my blood sugar level & 5 & 3 & 1 & 0 & 1 \\
\hline $\begin{array}{l}\text { 8. I have been motivated to take diabetes medications in } \\
\text { the correct time and dosage }\end{array}$ & 7 & 1 & 2 & 0 & 1 \\
\hline
\end{tabular}

Table 5 - Evaluation of the intervention structure.

\begin{tabular}{lcc} 
& Too many & Tuitable few \\
\hline Number of diary entries per day & 2 & 8 \\
Number of questions & 2 & 8 \\
Number of weeks completing the diaries & 1 & 9 \\
Number of feedback per day & 3 & 7 \\
Number of feedback per week & 0 & 8 \\
Number of weeks with daily feedback & 2 & 8 \\
Number of weeks with weekly feedback & 0 & 2 \\
\hline
\end{tabular}

